\title{
Human Full-Length Osteoprotegerin Induces the Proliferation of Rodent Vascular Smooth Muscle Cells both in vitro and in vivo
}

\author{
Riccardo Candido ${ }^{a}$ Barbara Toffolid $^{d}$ Federica Corallini $^{b}$ Stella Bernardi ${ }^{c}$ \\ Davide Zella ${ }^{\mathrm{e}}$ Rebecca Voltan ${ }^{c}$ Vittorio Grill ${ }^{\mathrm{b}}$ Claudio Celeghini ${ }^{\mathrm{b}}$ \\ Bruno Fabris ${ }^{c}$ \\ ${ }^{a}$ Diabetic Center, ASS 1 Triestina, ${ }^{b}$ Department of Biomedicine, ${ }^{c}$ Interdepartmental Center of Molecular Medicine, \\ University of Trieste, Trieste, and d Department of Morphology and Embryology, University of Ferrara, Ferrara, Italy; \\ ${ }^{\mathrm{e}}$ Institute of Human Virology - School of Medicine, University of Maryland, Baltimore, Md., USA
}

\section{Key Words}

Osteoprotegerin - Vascular smooth muscle cells .

Apolipoprotein E-null mice $\cdot$ Cell proliferation •

Atherosclerosis

\begin{abstract}
Background/Aims: Since elevated plasma levels of osteoprotegerin (OPG) represent a risk factor for death and heart failure in patients affected by diabetes mellitus and coronary artery disease, this study aimed to elucidate potential roles of OPG in the pathogenesis of atherosclerosis. Methods and Results: Recombinant human full-length OPG, used at concentrations comparable to the elevated levels found in the serum of diabetic patients, significantly increased the proliferation rate of rodent vascular smooth muscle cells (VSMC). To mimic the moderate chronic elevation of OPG observed in diabetic patients, low doses ( $1 \mu \mathrm{g} /$ mouse) of full-length human OPG were injected intraperitoneally every 3 weeks in diabetic apolipoprotein $\mathrm{E}(\mathrm{apoE})$-null mice. The group of animals treated for 12 weeks with recombinant OPG showed a small increase in the total aortic plaque area at necropsy in comparison to vehicle-treated animals. Importantly, while no differences in the amount of interstitial collagen or the degree of macrophage infiltration were observed between
\end{abstract}

OPG-treated and vehicle-treated apoE-null diabetic animals, a significant increase in the number of $\alpha$-actin-positive smooth muscle cells was observed in the plaques of OPGtreated mice. Conclusions: Our data suggest that OPG promotes VSMC proliferation and might be directly involved in pathogenetic aspects of atherosclerosis.

Copyright $\odot 2009$ S. Karger AG, Basel

\section{Introduction}

Osteoprotegerin (OPG), a soluble member of the tumor necrosis factor (TNF) receptor superfamily, was originally characterized for its ability to suppress osteoclastogenesis by binding to and inhibiting receptor activator of NF- $\kappa$ B ligand (RANKL), a member of the TNF superfamily of cytokines $[1,2]$. Subsequently, it has been shown that OPG can also interact with another member of the TNF superfamily, TNF-related apoptosis-inducing ligand (TRAIL), which shares approximately $25 \%$ amino acid homology with RANKL [3] and participates together with RANKL and OPG in the control of osteoclastogenesis [4-6]. Interestingly, a recent study has demonstrated that the affinity of OPG for TRAIL is slightly lower than but comparable to that for RANKL [7].

\section{KARGER}

Fax +4161306 1234 E-Mail karger@karger.ch www.karger.com
(C) 2009 S. Karger AG, Basel

$1018-1172 / 10 / 0473-0252 \$ 26.00 / 0$

Accessible online at:

www.karger.com/jvr
Dr. Claudio Celeghini

Department of Biomedicine, University of Trieste

Via Manzoni 16

IT-34100 Trieste (Italy)

Tel. +39 040558 6000, Fax +390405586018,E-Mail cceleghini@units.it 
Several studies have clearly demonstrated that the serum levels of OPG are elevated in diabetic and nondiabetic patients affected by cardiovascular diseases, and increased levels of OPG represent a risk factor for cardiovascular mortality, especially in diabetic patients [8-21]. However, in spite of the reported findings, the physiopathological role of elevated serum levels of OPG in vascular biology is not well understood. In this context, a possible pathogenetic link between elevated levels of OPG and inflammation has been suggested by recent in vitro studies of our group [22] and that of Mangan et al. [23] demonstrating that exposure to recombinant OPG promotes leukocyte adhesion to endothelial cells. These findings are particularly noteworthy since atherosclerosis, which constitutes the single most important contributor to the growing burden of cardiovascular disease, is regarded as a form of chronic low-grade inflammatory process which can ultimately lead to the development of complex lesions, or plaques, that protrude into the arterial lumen [24]. Moreover, it has recently been demonstrated that OPG might be involved in the pathogenesis of pulmonary hypertension by promoting the growth of human vascular smooth muscle cells (VSMC) obtained from pulmonary artery [25].

The aim of this study was to investigate whether OPG is involved in pathogenetic aspects of atherosclerosis. For this purpose, the effect of increasing concentrations of human recombinant OPG, comparable to those found in the plasma of diabetic patients [14], was investigated in rodent VSMC. In addition, recombinant full-length OPG was administered in vivo in an experimental model of atherosclerosis represented by apolipoprotein E (apoE)null diabetic mice. Upon induction of diabetes mellitus by streptozotocin injection, atherosclerotic lesions develop over time in these animals and resemble in appearance and distribution those observed in humans [26].

\section{Materials and Methods}

\section{Cell Cultures}

Primary rat aortic VSMC were purified as previously described and used between passages 3 and 6 [27]. Expression of lineage-specific markers was monitored by immunofluorescence analysis with anti- $\alpha$-smooth muscle actin ( $\alpha$-SMA) antibody (Dako, Copenhagen, Denmark). For cell cycle analysis, rodent VSMC were seeded at a low cell density and made quiescent by using serum-reduced $(0.1 \%$ FBS $)$ medium before incubation with 5-bromodeoxyuridine (BrdU; Sigma, St. Louis, Mo., USA) at $37^{\circ} \mathrm{C}$ for $1 \mathrm{~h}$. Anti-BrdU antibody was bound to BrdU incorporated into neosynthesized DNA, and the complex was detected by fluorescein isothiocyanate-conjugated secondary antibody. Cells were stained with propidium iodide and analyzed by flow cytometry. To avoid nonspecific fluorescence from dead cells, live cells were gated tightly using forward and side scatter, as described elsewhere [28].

\section{Animals and Experimental Protocol}

Animal care and treatment conformed to institutional guidelines in compliance with national and international laws and policies (EEC Council Directive 86/609, OJL 358, 12 December 1987). Six-week-old apoE-null mice $(n=20)$ were rendered diabetic by 5 daily intraperitoneal injections of streptozotocin (Sigma Chemical Co., St. Louis, Mo., USA) at a dose of $55 \mathrm{mg} / \mathrm{kg}$ body weight. The animals were maintained on regular mouse chow. Diabetic animals were further randomized to receive an intraperitoneal injection of either human recombinant OPG (R\&D Systems, Minneapolis, Minn., USA; $1 \mu \mathrm{g} / \mathrm{mouse}$ in a total of $200 \mu \mathrm{l}$ of HEPESbuffered saline) or an equivalent volume of vehicle, every 3 weeks. After 3 months, the animals were anesthetized by an intraperitoneal injection of pentobarbital sodium $(60 \mathrm{mg} / \mathrm{kg}$ body weight) and sacrificed for blood tests and histological examination. In each group of animals, serum glucose, glycosylated hemoglobin $\left(\mathrm{HbA}_{1 \mathrm{c}}\right)$, systolic blood pressure, triglycerides and total and highdensity lipoprotein (HDL) cholesterol were determined as previously described $[26,29]$. Human OPG levels were measured in mouse serum samples using a sandwich-type enzyme-linked immunosorbent assay (ELISA) kit (Alexis Biochemicals, Lausen, Switzerland), which does not cross-react with mouse OPG, according to the manufacturer's instructions. Mouse RANKL and OPG serum levels were measured in mouse serum samples using ELISA kits from R\&D Systems. The results were read at an optical density of $450 \mathrm{~nm}$ using an Anthos 2010 ELISA reader (Anthos Labtec Instruments GmbH, Wals/Salzburg, Austria). Measurements were performed in duplicate.

\section{Evaluation of Atherosclerotic Plaques}

To analyze the atherosclerotic lesions, 2 complementary approaches were used: an en face whole approach and histological section evaluations. The en face approach was used to obtain information about the distribution and extent of atherosclerosis in the aorta, whereas microscopic histological analysis was used to evaluate the lesion composition and complexity, as previously described [26].

In brief, for the en face approach the entire aorta was opened longitudinally and stained with Sudan IV-Herxheimer's solution (Sigma), and lesion area measurements were performed by calculating the proportion of aortic intimal surface area occupied by the red stain in the arch, descending thoracic and abdominal aorta, with the use of a video-based image analysis program (MCID, Imaging Research, St. Catharines, Ont., Canada). All aortic segments were then embedded in paraffin, and $4-\mu \mathrm{m}$-thick crosssectional serial sections were obtained. For quantification of collagen content, aortic cross-sections were stained with either Masson trichrome or Sirius red, as previously described [26].

\section{Immunohistochemistry}

Aortic lesions were characterized for cell composition by immunohistochemical analysis of cross-sectional sections. For this purpose, after neutralization of endogenous peroxidase, paraffin-embedded sections of aorta were incubated with the following primary antibodies: $\alpha$-SMA (smooth muscle cell marker) and 
proliferating cell nuclear antigen (PCNA; both from Dako; diluted 1:50). Biotinylated immunoglobulins (diluted 1:200) were then applied as a secondary antibody, followed by horseradish peroxidase-conjugated streptavidin (Dako; diluted 1:625). The staining was visualized by reaction with 3,3'-diaminobenzidine tetrahydrochloride (Sigma). Macrophage detection was performed using the primary antibody for F4/80 (Serotec, Oxford, UK; diluted 1:200), followed by secondary antirat immunoglobulins (Vector Laboratories, Burlingame, Calif., USA; diluted 1:200) and a catalyzed signal amplification mouse amplification kit (Dako), following the manufacturer's instructions. Syndecan-1 detection was performed using monoclonal rat antimouse CD138 (BD Pharmingen, San Jose, Calif., USA; diluted 1:500), followed by secondary biotinylated rabbit antirat antibody (Vector Laboratories; diluted 1:200) and an ABC kit (Vector Laboratories), following the manufacturer's instructions.

After counterstaining with hematoxylin, all the sections were examined by light microscopy and digitized using a high-resolution camera. Atherosclerotic lesions were manually traced on the computer, taking care to exclude normal-appearing media and to include only the intimal/subintimal atherosclerotic lesions, and quantification of collagen staining and of the specific immunostaining within the plaques was assessed using the MCID image analysis system. All immunohistochemical quantifications were performed by 2 independent blinded observers and are shown as the percentage of stained areas or of positive cells.

\section{Real-Time Quantitative Reverse Transcription-Polymerase}

Chain Reaction

Three micrograms of total RNA extracted from each aorta were used to synthesize cDNA with the Superscript First Strand synthesis system for reverse transcription-polymerase chain reaction (RT-PCR; Gibco BRL, Grand Island, N.Y., USA). Angiopoietin 2 and vascular cell adhesion molecule-1 (VCAM-1) gene expression was analyzed by real-time quantitative RT-PCR using the Taqman system (ABI Prism 7900 HT, Perkin-Elmer Inc., Foster City, Calif., USA). Fluorescence for each cycle was quantitatively analyzed by an ABI Prism 7900 HT Sequence Detection System (Perkin-Elmer, PE Biosystems). Gene expression of the target sequences was normalized in relation to the expression of an endogenous control, $18 \mathrm{~S}$ ribosomal RNA (18S rRNA Taqman Control Reagent kit, ABI Prism 7900 HT, Perkin-Elmer). Primers and Taqman probes for angiopoietin 2 and VCAM-1 and the endogenous reference $18 \mathrm{~S}$ rRNA were designed with the help of Primer Express (ABI Prism 7900 HT, Perkin-Elmer). For amplification of the angiopoietin $2 \mathrm{cDNA}$, the forward primer was 5'-GTCCAACTACAGGATTCACCTTACAG-3' and the reverse primer was 5'-TTGTCCGAATCCTTTGTGCTAA-3'. The probe specific to angiopoietin 2 was FAM- $5^{\prime}$-CAGCCAACCAGGAAG$3^{\prime}$-MGB. For the VCAM-1 cDNA, the forward primer was 5'-AAGTCTGTGGATGGCTCGTACA-3' and the reverse primer was $5^{\prime}$-TCAGTCTTAGATTCACACTCGTATATGC-3'. The probe specific to VCAM-1 was FAM-5'-CGGCATCCTGCAGCTGTGCCT-3'-TAMRA. Each sample was tested in triplicate. Results were expressed relative to control aorta values.

\section{Statistical Analysis}

The mean, median, minimum and maximum values were calculated for each group of data. Box plots were used to show the medians and 25 th-75th percentiles. Data were analyzed by
ANOVA and the Mann-Whitney rank sum test. Comparison of group means was performed by the Bonferroni method. Correlation coefficients were calculated by Spearman's method. Statistical significance was defined as $\mathrm{p}<0.05$.

\section{Results}

Recombinant Full-Length OPG Promotes Proliferation of Primary Rodent VSMC

Since it has been previously demonstrated that OPG levels are significantly elevated in the plasma or serum of diabetic patients [14-21], in the first group of experiments we investigated whether exposure to recombinant fulllength human OPG had any effect on cell cycle progression of rodent VSMC, analyzed by BrdU incorporation (fig. 1). As shown in figure 1, full-length human OPG at concentrations similar to those found in human serum significantly $(\mathrm{p}<0.05)$ promoted the proliferation of VSMC [14].

\section{In vivo Injection of Low Concentrations of \\ Full-Length Recombinant Human OPG Induces a \\ Small but Significant Increase in Atherosclerotic \\ Plaques in apoE-Null Diabetic Mice}

After the induction of diabetes mellitus (3 weeks after streptozotocin injection), apoE-null mice were randomized to be injected intraperitoneally either with recombinant human OPG or vehicle. Using an ELISA kit specific for human OPG, the presence of human OPG was detectable, although at low levels, in the serum of OPG-injected animals $24 \mathrm{~h}$ after injection but not in the serum of animals injected with vehicle (fig. 2). Levels of human OPG similar to those found after $24 \mathrm{~h}$ were detectable in animal sera also 1 week after intraperitoneal injection (data not shown). It should be noted that repeated intraperitoneal injections of human recombinant OPG (every 3 weeks for 3 months) were well tolerated by the apoE-null mice. After 3 months, the diabetic animals were analyzed for various parameters and then sacrificed for pathological examinations. The body weight and systolic blood pressure as well as the levels of blood glucose, $\mathrm{HbA}_{1 \mathrm{c}}$, total cholesterol, HDL cholesterol and triglycerides were not significantly different in diabetic animals injected or not with human recombinant OPG (table 1). In addition, to ascertain whether the injection of human recombinant OPG might modulate the levels of endogenous mouse OPG and RANKL, the levels of these molecules were quantitatively evaluated by ELISA at the end of the experimental period. As shown in table 1, no significant 
Fig. 1. Recombinant human OPG promotes proliferation of primary rat aortic VSMC. Aortic VSMC were seeded at subconfluence, starved of serum and either left untreated or exposed to the indicated concentrations of OPG for $36 \mathrm{~h}$. After $\mathrm{BrdU} /$ propidium iodide staining, the percentage of cells in the $S$ phase of the cell cycle, which had incorporated BrdU, was calculated from the flow cytograms and expressed as the percentage of the total population. As positive control, cells were treated with insulin and are shown for comparison. Data are expressed as means $\pm \mathrm{SD}$ of results from 4 independent experiments. ${ }^{*} \mathrm{p}<0.05$ compared to untreated cells.

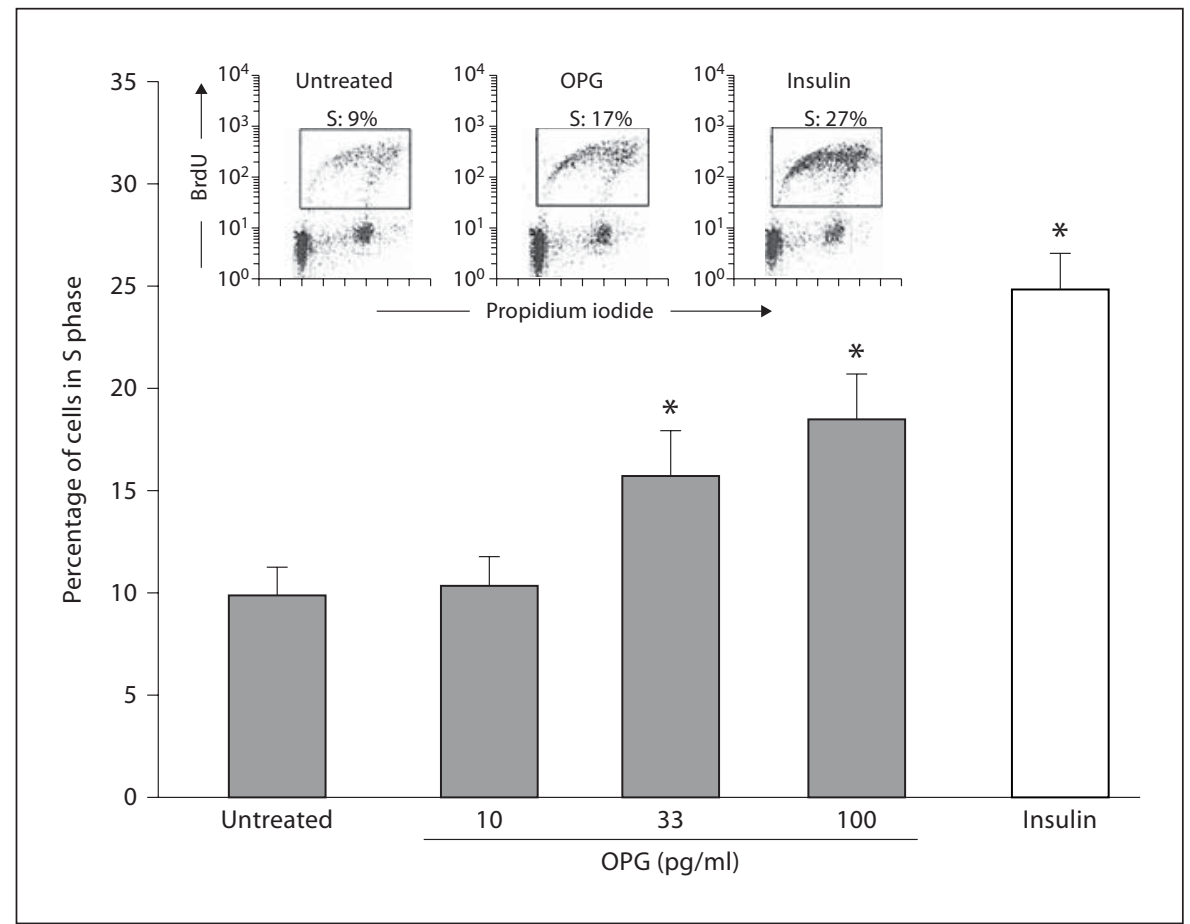

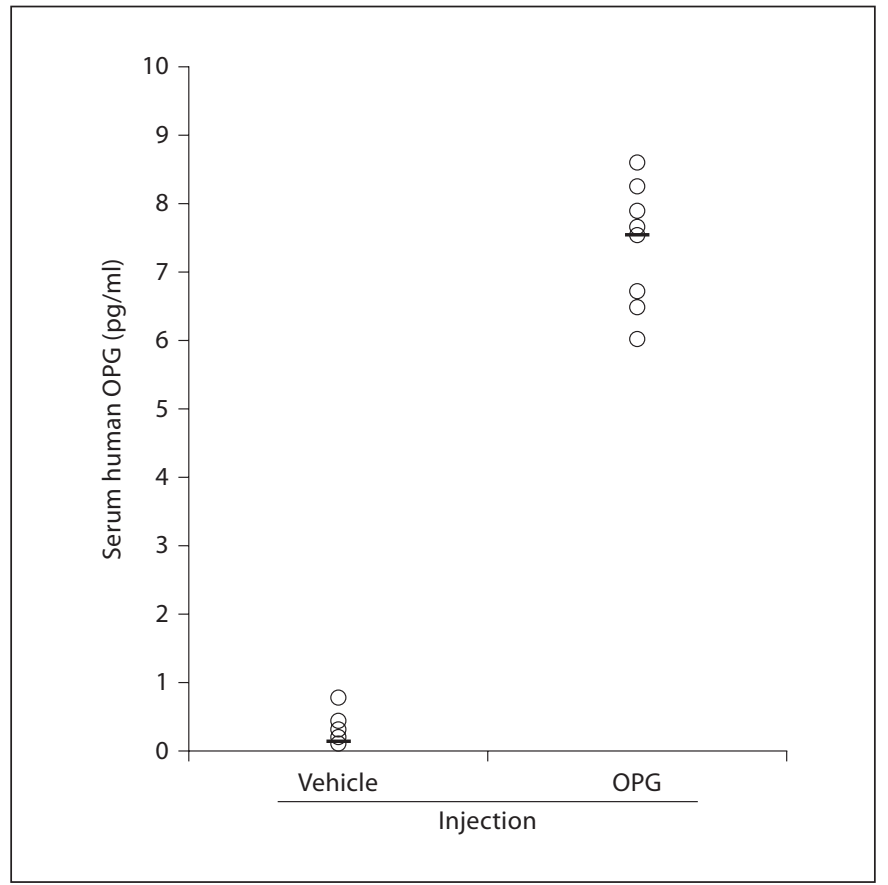

Fig. 2. Serum detection of human recombinant OPG in apoE-null diabetic mice. We used ELISA to analyze the levels of human OPG in the sera of apoE-null diabetic mice injected intraperitoneally with human recombinant OPG $(n=8)$ or vehicle $(n=8)$. All serum samples from vehicle-injected mice were below the detection limit of the assay. Each data point was determined in duplicate. differences in serum levels of OPG and RANKL were observed between mice injected with recombinant human OPG or vehicle. Unfortunately, it was not possible to measure the levels of TRAIL, the second ligand for OPG $[6,7]$, due to the lack of commercially available ELISA kits for mouse TRAIL.

En face dissection (fig. 3a) and cross-sectional serial sections (fig. 3b) showed the presence of plaque areas, characterized by asymmetrically thickened intima, in the entire aorta of apoE-null diabetic mice (fig. 3a, b). Of interest, OPG-treated animals exhibited a significantly $(\mathrm{p}<0.05)$ increased total plaque area compared to the mice injected with vehicle (fig. $3 \mathrm{a}$ ). Such an increase could not be ascribed to an aspecific, allergic or toxic effect consequent to the injection of a human protein in the apoEnull animals since the administration of recombinant human TRAIL induced the opposite effect, decreasing the total plaque area [29].

\section{The in vivo Injection of Recombinant Human OPG Modulates the Histological Composition of} Atherosclerotic Plaques in apoE-Null Diabetic Mice

We next investigated whether, besides increasing the extent of atherosclerotic lesions, OPG treatment also affected the histological composition of the plaques. For this purpose, cross-sectional serial sections of the aortic 


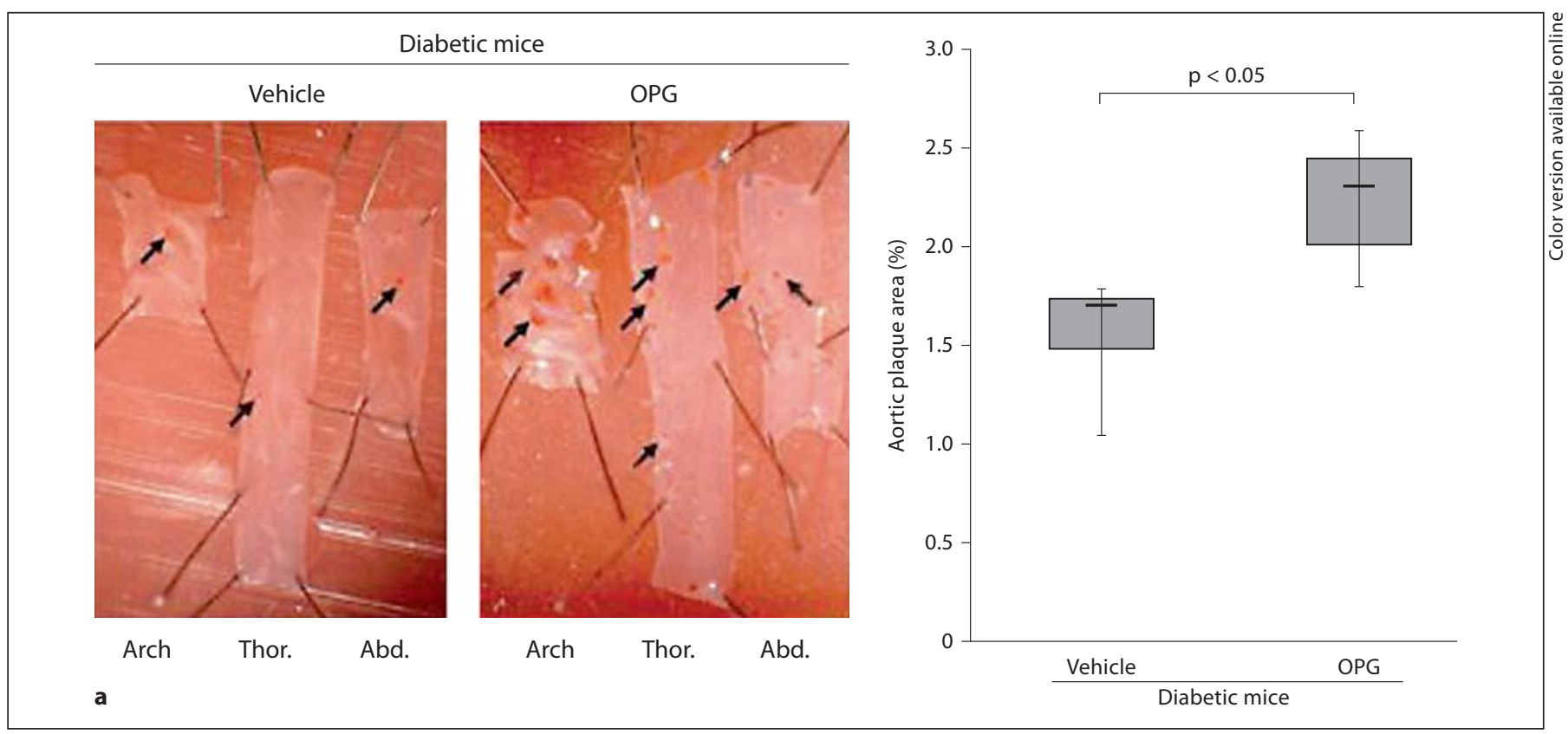

Fig. 3. Recombinant OPG increased the extent of atherosclerotic plaques in apoE-null diabetic mice. a Representative examples of en face dissection of aortic arch and thoracic and abdominal aorta, stained with Sudan IV, showing atherosclerotic lesions (arrows) in apoE-null diabetic mice injected intraperitoneally with either vehicle $(n=10)$ or recombinant OPG $(n=10)$. Atherosclerotic involvement for each mouse was quantitatively determined by measuring the proportion of aortic intimal surface area stained red (Sudan IV-positive) in each of the 3 aortic segments. Horizontal bars are medians of the percentage of plaque area in the total aortas, upper and lower edges of the boxes are 75th and 25th percentiles and vertical lines are 10th and 90th percentiles. b Representative hematoxylin-eosin-stained histological cross-sections are shown. Original magnification $\times 20$.

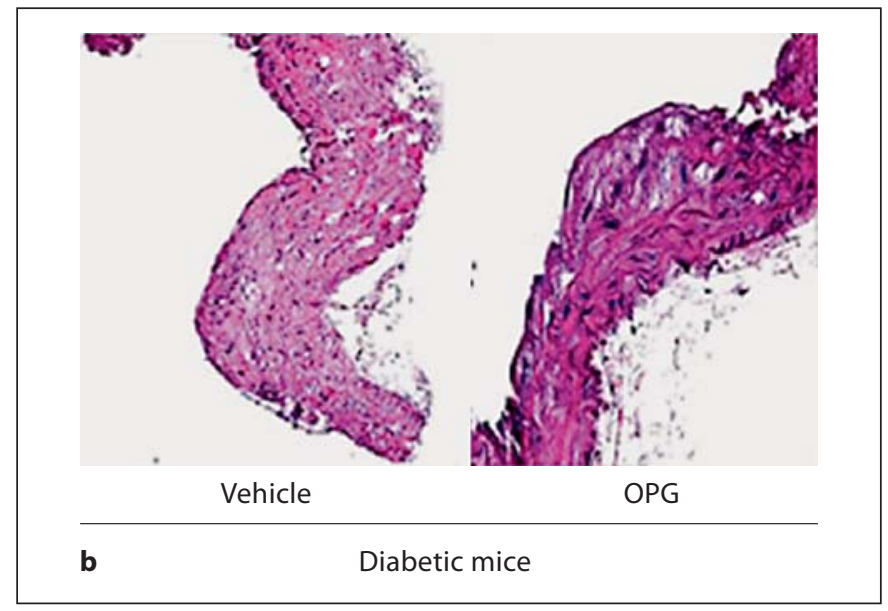

Table 1. Characteristics of the mice at the end of the study

\begin{tabular}{lcc}
\hline Parameters & $\begin{array}{c}\text { Vehicle-treated } \\
\text { mice }(\mathrm{n}=10)\end{array}$ & $\begin{array}{c}\text { rOPG-treated } \\
\text { mice }(\mathrm{n}=10)\end{array}$ \\
\hline Body weight, g & $25 \pm 3$ & $23 \pm 3$ \\
Serum glucose, mg/dl & $550 \pm 42$ & $531 \pm 39$ \\
HbA $_{1 \mathrm{c}} \%$ & $14.1 \pm 1.2$ & $13.3 \pm 1.3$ \\
Systolic blood pressure, mm Hg & $87 \pm 9$ & $94 \pm 8$ \\
Total cholesterol, mg/dl & $910 \pm 107$ & $949 \pm 119$ \\
Triglycerides, mg/dl & $208 \pm 43$ & $199 \pm 17$ \\
HDL cholesterol, mg/dl & $116 \pm 27$ & $91 \pm 12$ \\
Mouse serum OPG, pg/ml & $310 \pm 74$ & $320 \pm 69$ \\
Mouse serum RANKL, pg/ml & $103 \pm 11.2$ & $119 \pm 30.6$ \\
\hline
\end{tabular}

$\mathrm{rOPG}=$ Recombinant $\mathrm{OPG}$.

atherosclerotic lesions of apoE-null diabetic mice were quantitatively analyzed by immunohistochemistry for the presence of collagen and the cell composition of the plaques (fig. 4, 5). Of note, no significant differences in the collagen content or in the percentage of infiltrating macrophages were observed between OPG- and vehicleinjected mice (fig. 4a, b). Similarly, the levels of syndecan-1, which has been proposed to act as a ligand for OPG in multiple myeloma [30], were not changed in the aortas of OPG-injected mice with respect to vehicle-treated animals (data not shown).

On the other hand, the percentage of VSMC ( $\alpha$-SMApositive cells) was significantly $(\mathrm{p}<0.05)$ increased in the aortic lesions of OPG-injected apoE-null animals 
Fig. 4. Recombinant human OPG did not affect the interstitial collagen content or macrophage infiltration in the atherosclerotic plaques of apoE-null diabetic mice. Serial sections from aortas of apoE-null diabetic mice injected intraperitoneally with either vehicle $(n=10)$ or recombinant OPG $(n=10)$ were analyzed to quantitatively evaluate the interstitial collagen content as well as the presence/percentage of macrophages (using F4/80 marker) in the aortic intima. Staining results, representatively shown in a (original magnification $\times 20$ ), were quantitatively determined in each mouse with the MCID video-based image analysis program and expressed as the percentage of stained area. In b, horizontal bars are medians, upper and lower edges of the boxes are 75 th and 25 th percentiles and vertical lines are 10 th and 90 th percentiles.
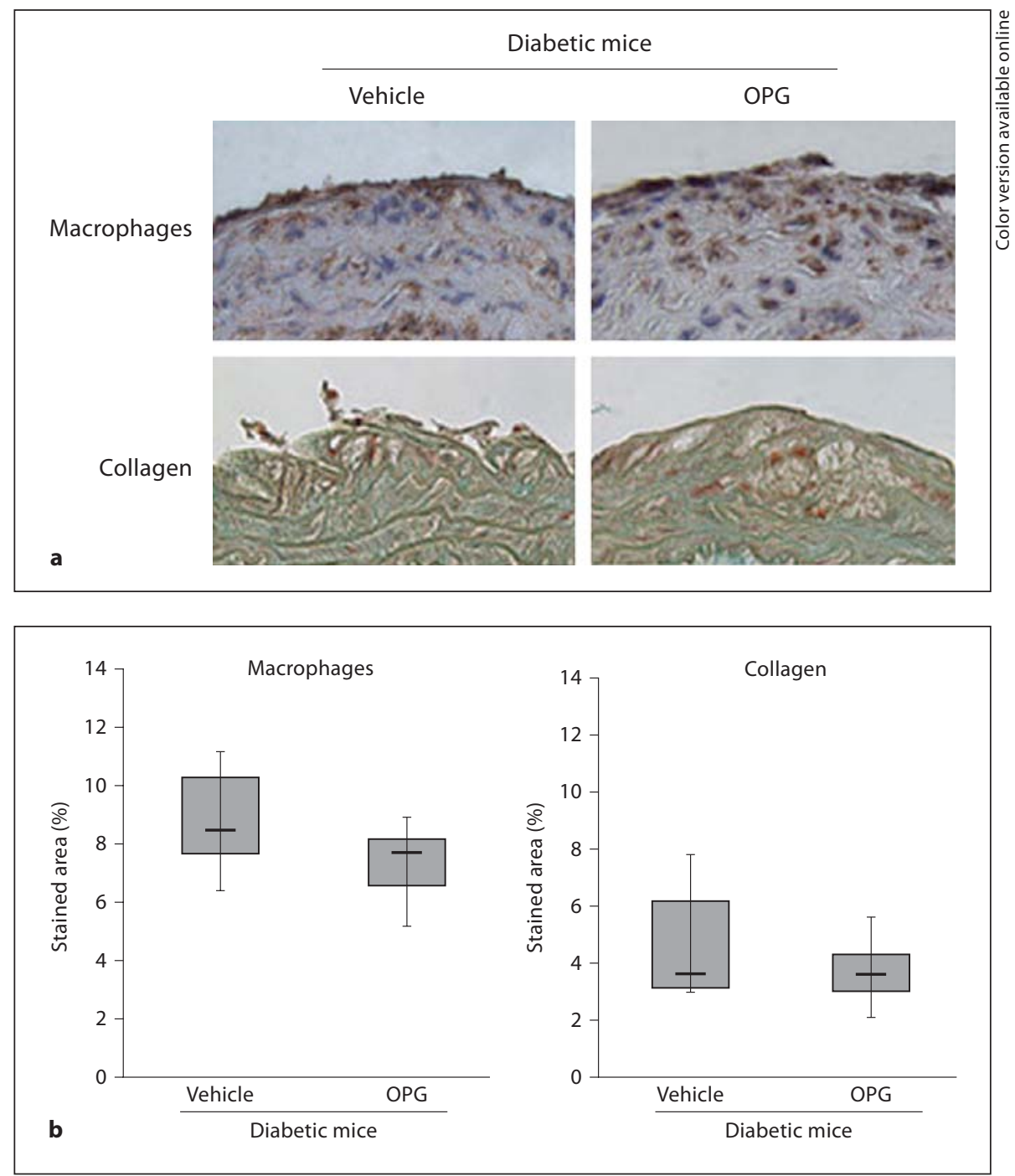

compared to diabetic animals injected with vehicle (fig. 5a, b). To elucidate whether the increased content of VSMC in the plaques of OPG-treated animals was accompanied by an increase in cell proliferation, we analyzed the percentage of PCNA-positive cells, which accurately reflects the degree of cell proliferation, within the plaques. As shown in figure $5 \mathrm{a}$ and b, OPG administration induced a significant $(\mathrm{p}<0.01)$ increase in PCNApositive cells. Interestingly, the percentage of PCNApositive cells evaluated in all animals showed a significant positive correlation with the percentage of the $\alpha$-SMA-positive area evaluated in the plaques of each mouse $(\mathrm{R}=0.76, \mathrm{p}<0.05)$, suggesting that VSMC were the major cell type involved in cell proliferation within the plaques.
Treatment with Recombinant Human OPG Increases the mRNA Expression of Angiopoietin 2 in the Aorta of apoE-Null Animals

Taking into consideration the fact that a recent in vitro study demonstrated that angiopoietin 2 plays a key role in promoting inflammation of the vessel wall [31], we next investigated whether the in vivo administration of human OPG was able to modulate angiopoietin 2 expression in the aortic wall of apoE-null mice. The constitutive steady-state mRNA levels of angiopoietin 2 were quantitatively evaluated by real-time RT-PCR in RNA extracted from aortic samples of OPG- and vehicle-treated mice (fig. 6). The mRNA levels of angiopoietin 2 were significantly $(\mathrm{p}<0.05)$ higher in the aortas of OPG-treated animals than in the aortas obtained from vehicle-treated 
Fig. 5. Recombinant human OPG increased the content of VSMC and their proliferative activity in the atherosclerotic plaques of apoE-null diabetic mice. Serial sections from aortas of apoE-null diabetic mice injected intraperitoneally with either vehicle $(\mathrm{n}=10)$ or recombinant OPG $(\mathrm{n}=$ 10) were analyzed to quantitatively evaluate the presence/percentage of VSMC (using $\alpha$-SMA marker) and the content of PCNA-positive cells in the aortic intima. Staining results, representatively shown in a (original magnification $\times 20$ ), were quantitatively determined in each mouse with the MCID video-based image analysis program and expressed as the percentage of stained area or of positive cells. In $\mathbf{b}$, horizontal bars are medians, upper and lower edges of the boxes are 75 th and 25th percentiles and vertical lines are 10th and 90th percentiles.
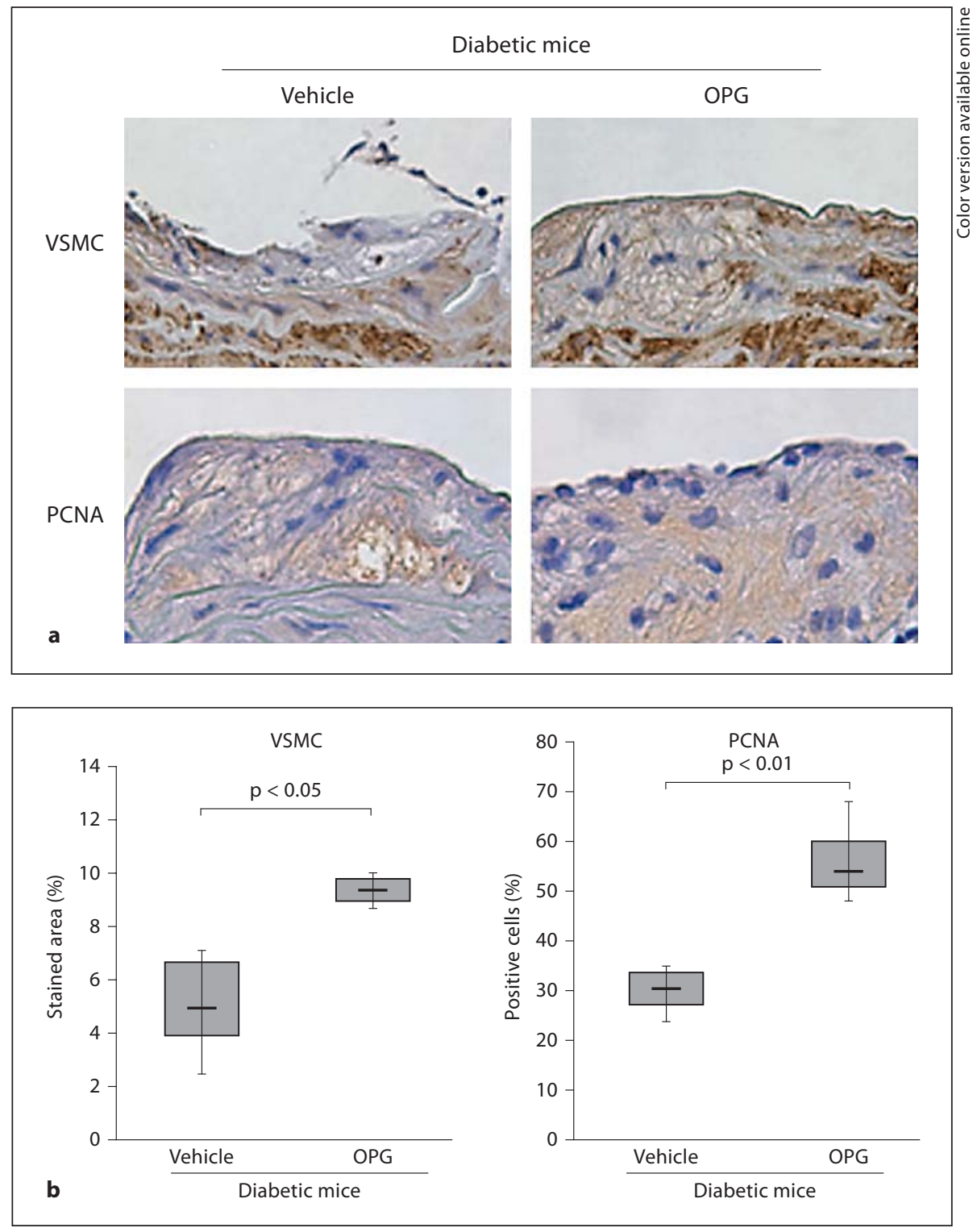

animals (fig. 6). On the other hand, the inflammatory cell adhesion molecule VCAM-1 [32] did not show significant modifications in OPG-treated versus vehicletreated mice (fig. 6).

\section{Discussion}

Several studies have demonstrated that increased amounts of serum OPG correlate with increased cardiovascular risk in both diabetic and nondiabetic patients [8-21]. Possible interpretations of this positive relationship include OPG playing an active role in disease pro- gression, or OPG serving as a compensatory response to minimize disease progression, or OPG representing a noncompensatory (neutral) response to disease. The interpretation that OPG serum elevation represents a compensatory mechanism mainly relies on studies performed on OPG knockout mice showing a protective role of OPG against vascular calcifications [33-35]. However, in each of these model systems, the prevention of vascular calcification by OPG was associated with strong suppression of bone turnover. Moreover, both recombinant OPG [34] and bisphosphonate [36] treatments of rats suppressed vascular calcification in a warfarin model of vascular calcification, in association with suppression of bone turn- 


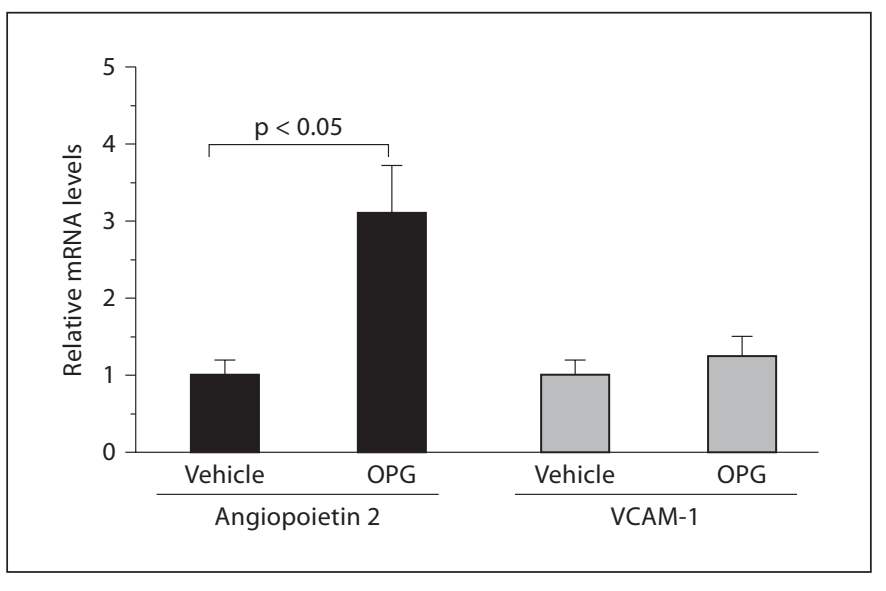

Fig. 6. Comparison of angiopoietin 2 and VCAM-1 steady-state mRNA levels between aortas from OPG- and vehicle-treated apoE-null diabetic mice. mRNA levels of angiopoietin 2 and VCAM-1 in RNA extracted from aortic samples of OPG-treated $(\mathrm{n}=4)$ and vehicle-treated $(\mathrm{n}=4)$ apoE-null diabetic mice were quantitatively analyzed by real-time RT-PCR. After normalization to the level of $18 \mathrm{~S}$ mRNA, gene-specific RNA levels in control aortas (from vehicle-treated mice) were set as 1 . Values are means \pm SD of triplicate determinations.

over. Taken together, these studies [33-36] suggest that the ability of OPG to inhibit vascular calcification is an indirect effect of its antiosteoclastic activity. In contrast, in vitro studies have demonstrated that the expression and release of OPG by vascular cells is markedly upregulated in response to inflammatory cytokines, such as TNF- $\alpha$ and platelet-derived growth factor $[37,38]$, and that OPG promotes leukocyte adhesion to endothelial cells $[22,23]$, suggesting an active role of OPG in disease progression.

In order to try to mimic the effect of a small elevation of OPG serum levels, in this study we adopted a strategy of delivering human OPG intraperitoneally to allow a prolonged release of low levels of OPG into the general circulation. In considering the relative levels of human and mouse OPG detected by ELISA in the sera of OPGinjected animals, also in relationship to the concentration of recombinant human OPG used in both in vitro and in vivo experiments, it should be taken into account that the commercial ELISAs used to detect either human or mouse OPG may have different sensitivities. Moreover, it has recently been demonstrated that OPG rapidly adheres to the vascular wall through its heparin-binding domain [39], and therefore it is conceivable that the levels of circulating OPG do not reflect the real amount of OPG in the vascular microenvironment. In spite of this cautionary consideration, it is noteworthy that human OPG could be detected in the general circulation of mice injected intraperitoneally with human OPG for at least 1 week after injection. We were able to demonstrate that repeated injections in apoE-null mice of relatively low concentrations of human OPG resulted in a significant increase in the total plaque area. Taking into account the fact that we previously demonstrated in a series of in vitro and in vivo experiments that soluble recombinant TRAIL shows anti-inflammatory [40-42] and antiatherosclerotic [29] activity, one mechanism by which OPG might accelerate the development of atherosclerotic lesions is through the inhibition of soluble circulating TRAIL. Consistent with this interpretation, it has previously been shown that soluble TRAIL levels have a tendency to decrease in the sera of patients affected by cardiovascular diseases $[43,44]$. Moreover, the demonstration that OPG significantly increases the mRNA expression of angiopoietin 2 at the aortic level is in line with the results of a recent in vitro study [23]. Since angiopoietin 2 has been shown to play a key role in the early steps of atherosclerosis [31], the ability of OPG to increase the expression of angiopoietin 2 might represent an important additional pathogenetic mechanism to explain the ability of OPG to promote atherosclerosis. On the other hand, we also noticed a slight trend for an increase in systolic blood pressure in the OPG-treated mice (table 1), which might account for the changes observed in atherosclerotic plaques, but we were unable to perform hemodynamic assessments that may have provided additional information.

It is also noteworthy that the plaques in OPG-treated mice showed a significant increase in the number of VSMC. In line with our finding that OPG increases the number of proliferating VSMC in aortic plaques of apoE ${ }^{-/-}$knockout mice, a study performed on OPG/apoE double $\left(\mathrm{OPG}^{-/-} \mathrm{apoE}^{-/-}\right)$knockout mice [35] demonstrated that the atherosclerotic lesions observed in these mice were characterized by a severe reduction in the number of smooth muscle cells, which rendered these plaques unstable. Moreover, in keeping with our finding that recombinant full-length OPG promotes rodent VSMC proliferation in vitro, a recent study has demonstrated that recombinant OPG is able to significantly increase the proliferation of cultured human pulmonary VSMC [25].

Our present findings should also be considered in the light of a recent study by Morony et al. [45], who demonstrated that subcutaneous injection of pharmacological concentrations of human recombinant OPG (OPG-Fc) decreased the degree of atherosclerotic calcified lesions 
in diet-fed atherogenic $\mathrm{ldlr}^{-/-}$mice, without affecting the total burden of atherosclerotic lesions. The most likely explanation to reconcile the findings of Morony et al. [45] with our present findings is that Morony et al. [45] used human OPG-Fc rather than native human full-length OPG. In OPG-Fc, the signal peptide, heparin-binding domain and death domain homologous regions are removed [46], and we and others have previously shown that the heparin-binding domain of OPG is essential to mediate important proinflammatory effects of OPG [7, $22,23]$. Moreover, it has been shown that surface proteoglycans, which mediate interactions with the heparinbinding domain of OPG $[7,22]$, play a key role in promoting VSMC migration and proliferation [47].

Besides contributing to vessel wall inflammation and lipoprotein retention, VSMC play a key role in the formation of the fibrous cap that provides stability to plaques, preserving them from rupture, and therefore the benefit/ risk of therapeutic inhibition of VSMC proliferation in atherosclerosis is unclear [24]. In this context, the effect of OPG on plaque formation seems to be twofold; on the one hand, it increases the extent of the total plaque area, but on the other hand, it may contribute to plaque stability by promoting the proliferation of VSMC. Anyhow, although one must be cautious in extrapolating these experimental data to the clinical context, an important implication of our data is that denosumab, a fully human monoclonal antibody which blocks osteoclastogenesis by inhibiting RANKL [46], might be preferable to recombinant OPG for the treatment of pathologies associated with high bone turnover, such as osteoporosis.

\section{Acknowledgments}

This work was supported by the CRTrieste Foundation and by the 'Università di Trieste-Progetto Giovani Ricercatori 2007'.

\section{References}

1 Simonet WS, Lacey DL, Dunstan CR, Kelley M, Chang MS, Lüthy R, Nguyen HQ, Wooden S, Bennett L, Boone T, Shimamoto G, DeRose M, Elliott R, Colombero A, Tan HL, Trail G, Sullivan J, Davy E, Bucay N, Renshaw-Gegg L, Hughes TM, Hill D, Pattison W, Campbell P, Sander S, Van G, Tarpley J, Derby P, Lee R, Boyle WJ: Osteoprotegerin: a novel secreted protein involved in the regulation of bone density. Cell 1997;89:309319.

\2 Hsu H, Lacey DL, Dunstan CR, Solovyev I, Colombero A, Timms E, Tan HL, Elliott G, Kelley MJ, Sarosi I, Wang L, Xia XZ, Elliott R, Chiu L, Black T, Scully S, Capparelli C, Morony S, Shimamoto G, Bass MB, Boyle WJ: Tumor necrosis factor receptor family member RANK mediates osteoclast differentiation and activation induced by osteoprotegerin ligand. Proc Natl Acad Sci USA 1999;96:3540-3545.

-3 Zauli G, Secchiero P: The role of the TRAIL/ TRAIL-receptors system in hematopoiesis and endothelial cell biology. Cytokine Growth Fact Rev 2006;17:245-247.

-4 Zauli G, Rimondi E, Nicolin V, Melloni E, Celeghini C, Secchiero P: TNF-related apoptosis inducing ligand (TRAIL) blocks osteoclastic differentiation induced by RANKL + M-CSF. Blood 2004;104:2044-2050.

$\checkmark 5$ Chamoux E, Houde N, L’Eriger K, Roux S: Osteoprotegerin decreases human osteoclast apoptosis by inhibiting the TRAIL pathway. J Cell Physiol 2008;216:536-542.
-6 Zauli G, Rimondi E, Stea S, Baruffaldi F, Stebel M, Zerbinati C, Corallini F, Secchiero P: TRAIL inhibits osteoclastic differentiation by counteracting RANKL-dependent p $27^{\mathrm{Kipl}}$ accumulation in pre-osteoclast precursors. J Cell Physiol 2008;214:117-125.

7 Vitovski S, Phillips JS, Sayers J, Croucher PI Investigating the interaction between osteoprotegerin and RANKL or TRAIL: evidence for a pivotal role for osteoprotegerin in regulating two distinct pathways. J Biol Chem 2007;282:31601-31609.

8 Jono S, Ikari Y, Shioi A, Mori K, Miki T, Hara K, Nishizawa Y: Serum osteoprotegerin levels are associated with the presence and severity of coronary artery disease. Circulation 2002;106:1192-1194.

-9 Schoppet M, Sattler AM, Schaefer JR, Herzum M, Maisch B, Hofbauer LC: Increased osteoprotegerin serum levels in men with coronary artery disease. J Clin Endocrinol Metab 2003;88:1024-1028.

$\checkmark 10$ Kiechl S, Schett G, Wenning G, Redlich K, Oberhoolenser M, Mayr A, Santer P, Smolen J, Poewe W, Willeit J: Osteoprotegerin is a risk factor for progressive atherosclerosis and cardiovascular disease. Circulation 2004;109:2175-2180.

-11 Ueland T, Jemtland R, Godang K, Kjekshus J, Hognestad A, Omland T, Squire IB, Gullestad L, Bollerslev J, Dickstein K, Aukrust P. Prognostic value of osteoprotegerin in heart failure after acute myocardial infarction. J Am Coll Cardiol 2004;44:1970-1976.
12 Ueland T, Yndestad A, Øie E, Florholmen G, Halvorsen B, Frøland SS, Simonsen S, Christensen G, Gullestad L, Aukrust P: Dysregulated osteoprotegerin/RANK ligand/RANK axis in clinical and experimental heart failure. Circulation 2005;111:2461-2468.

13 Moran CS, McCann M, Karan M, Normal P, Ketheesan N, Golledge J: Association of osteoprotegerin with human abdominal aortic aneurysm progression. Circulation 2005; 111:3119-3125.

14 Secchiero P, Corallini F, Pandolfi A, Consoli A, Candido R, Fabris B, Celeghini C, Capitani S, Zauli G: An increased osteoprotegerin (OPG) serum release characterizes the early onset of diabetes mellitus and may contribute to endothelial cell dysfunction. Am J Pathol 2006;169:2236-2244.

$\checkmark 15$ Shin JY, Shin YG, Chun CH: Elevated serum osteoprotegerin levels are associated with vascular endothelial dysfunction in type 2 diabetes. Diabetes Care 2006;29:1664-1666.

16 Abedin M, Omland T, Ueland T, Khera A, Aukrust P, Murphy SA, Jain T, Gruntmanis U, McGuire DK, de Lemos JA: Relation of osteoprotegerin to coronary calcium and aortic plaque. Am J Cardiol 2007;99:513-518

17 Helske S, Kovanen PT, Lindstedt KA, Salmela K, Lommi J, Turto H, Werkkala K, Kupari $\mathrm{M}$ : Increased circulating concentrations and augmented myocardial extraction of osteoprotegerin in heart failure due to left ventricular pressure overload. Eur J Heart Fail 2007; 28:1894-1903. 
-18 Avignon A, Sultan A, Piot C, Mariano-Goulart D, Thuan Dit Dieudonné JF, Cristol JP, Dupuy AM: Osteoprotegerin: a novel independent marker for silent myocardial ischemia in asymptomatic diabetic patients. Diabetes Care 2007;30:2934-2939.

19 Omland T, Ueland T, Jansson AM, Persson A, Karlsson T, Smith C, Herlitz J, Aukrust P, Hartford M, Caidahl K: Circulating osteoprotegerin levels and long-term prognosis in patients with acute coronary syndromes. J Am Coll Cardiol 2008;51:627-633.

20 Jorsal A, Tarnow L, Flyvbjerg A, Parving $\mathrm{HH}$, Rossing P, Rasmussen LM: Plasma osteoprotegerin levels predict cardiovascular and all-cause mortality and deterioration of kidney function in type 1 diabetic patients with nephropathy. Diabetologia 2008;51: 2100-2107.

21 Nybo M, Rasmussen L: The capability of plasma osteoprotegerin as a predictor of cardiovascular disease: a systematic literature review. Eur J Endocrinol 2008;159:603-608.

22 Zauli G, Corallini F, Bossi F, Fischetti F, Durigutto $\mathrm{P}$, Celeghini C, Tedesco F, Secchiero P: Osteoprotegerin increases leukocyte adhesion to endothelial cells both in vitro and in vivo. Blood 2007;110:536-543.

-23 Mangan SH, Campenhout AV, Rush C, Golledge J: Osteoprotegerin upregulates endothelial cell adhesion molecule response to tumor necrosis factor- $\alpha$ associated with induction of angiopoietin-2. Cardiovasc Res 2007;76:494-505.

24 Libby P: Inflammation in atherosclerosis. Nature 2002;420:868-874.

25 Lawrie A, Waterman E, Southwood M, Evans D, Suntharalingam J, Francis S, Crossman D, Croucher P, Morrell N, Newman C: Evidence of a role for osteoprotegerin in the pathogenesis of pulmonary arterial hypertension. Am J Pathol 2008;172:256-264.

-26 Candido R, Allen TJ, Lassila M, Cao Z, Thallas V, Cooper ME, Jandeleit-Dahm KA: Irbesartan but not amlodipine suppresses diabetes-associated atherosclerosis. Circulation 2004;109:1536-1542.

$\checkmark 27$ Secchiero P, Zerbinati C, Rimondi E, Corallini F, Milani D, Grill V, Forti G, Capitani S, Zauli G: TRAIL promotes the survival, migration and proliferation of vascular smooth muscle cells. Cell Mol Life Sci 2004;61:19651974.

-28 Borgatti P, Zauli G, Colamussi ML, Gibellini D, Previati M, Cantley L, Capitani S: Extracellular HIV-1 Tat protein activates phosphatidylinositol 3- and Akt/PKB kinases in CD4+ T lymphoblastoid Jurkat cells. Eur J Immunol 1997;27:2805-2811.
29 Secchiero P, Candido R, Corallini F, Zacchigna S, Toffoli B, Rimondi E, Fabris B, Giacca M, Zauli G: Systemic TRAIL delivery shows anti-atherosclerotic activity in apoE-null diabetic mice. Circulation 2006;114:15221530.

30 Standal T, Seidel C, Hjertner O, Plesner T, Sanderson RD, Waage A, Borset M, Sundan A: Osteprotegerin is bound, internalized and degraded by multiple myeloma cells. Blood 2002;100:3002-3007.

-31 Fiedler U, Reiss Y, Scharpfenecker M, Grunow V, Koidl S, Thurston G, Gale NW, Witzenrath M, Rosseau S, Suttorp N, Sobke A, Herrmann M, Preissner KT, Vajkoczy P, Augustin HG: Angiopoietin-2 sensitizes endothelial cells to TNF- $\alpha$ and has a crucial role in the induction of inflammation. Nat Med 2006;12:235-239.

32 Wara AK, Mitsumata M, Yamane T, Kusumi Y, Yoshida Y: Gene expression in endothelial cells and intimal smooth muscle cells in atherosclerosis-prone and atherosclerosis-resistant regions of the human aorta. J Vasc Res 2008;45:303-313.

33 Bucay N, Sarosi I, Dunstan CR, Morony S, Tarpley J, Capparelli C, Scully S, Tan HL, Xu W, Lacey DL, Boyle WJ, Simonet WS: Osteoprotegerin-deficient mice develop early onset osteoporosis and arterial calcification. Genes Dev 1998;12:1260-1268.

34 Price PA, June HH, Buckley JR, Williamson MK: Osteoprotegerin inhibits artery calcification induced by warfarin and by vitamin D. Arterioscler Thromb Vasc Biol 2001;21: 1610-1616

35 Bennett BJ, Scatena M, Kirk EA, Rattazzi M, Varon RM, Averill M, Schwartz SM, Giachelli CM, Rosenfeld ME: Osteoprotegerin inactivation accelerates advanced atherosclerotic lesion progression and calcification in older $\mathrm{ApoE}^{-/-}$mice. Arterioscler Thromb Vasc Biol 2006;28:2117-2124.

36 Price PA, Faus SA, Williamson MK: Bisphosphonates alendronate and ibandronate inhibit artery calcification at doses comparable to those that inhibit bone resorption. Arterioscler Thromb Vasc Biol 2001;21:817-824.

37 Olesen P, Ledet T, Rasmussen LM: Arterial osteoprotegerin: increased amounts in diabetes and modifiable synthesis from vascular smooth muscle cells by insulin and TNFalpha. Diabetologia 2005;48:561-568.
38 Zhang J, Fu M, Myles D, Zhu X, Du J, Cao X, Chen YE: PDGF induces osteoprotegerin expression in vascular smooth muscle cells by multiple signal pathways. FEBS Lett 2002; 521:180-184.

39 Nybo M, Rasmussen LM: Osteoprotegerin released from the vascular wall by heparin mainly derives from vascular smooth muscle cells. Atherosclerosis 2008, E-pub ahead of print.

-40 Secchiero P, Gonelli A, Carnevale E, Milani D, Pandolfi A, Zella D, Zauli G: TRAIL promotes the survival and proliferation of primary human vascular endothelial cells by activating the Akt and ERK pathways. Circulation 2003; 107:2250-2256.

41 Zauli G, Pandolfi A, Gonelli A, Di Pietro R, Guarnieri S, Ciabattoni G, Rana R, Vitale M, Secchiero P: TNF-related apoptosis-inducing ligand (TRAIL) sequentially up-regulates nitric oxide and prostanoid production in primary human endothelial cells. Circ Res 2003;92:732-740

42 Secchiero P, Corallini F, di Iasio MG, Gonelli A, Barbarotto E, Zauli G: TRAIL counteracts the proadhesive activity of inflammatory cytokines in endothelial cells by down-modulating CCL8 and CXCL10 chemokine expression and release. Blood 2005; 105: 3413-3419.

-43 Schoppet M, Sattler AM, Schaefer JR, Hofbauer LC: Osteoprotegerin (OPG) and tumor necrosis factor-related apoptosis-inducing ligand (TRAIL) levels in atherosclerosis. Atherosclerosis 2006; 184:446-447.

44 Michowitz Y, Goldstein E, Roth A, Afek A, Abashidze A, Ben Gal Y, Keren G, George J: The involvement of tumor necrosis factorrelated apoptosis-inducing ligand (TRAIL) in atherosclerosis. J Am Coll Cardiol 2005; 45:1018-1024.

-45 Morony S, Tintut Y, Zhang Z, Cattley RC, Van G, Dwyer D, Stolina M, Kostenuik PJ, Demer LL: Osteoprotegerin inhibits vascular calcification without affecting atherosclerosis in $l d l r(-/-)$ mice. Circulation 2008; 117:411-420.

$\checkmark 46$ Kearns AE, Khosla S, Kostenuik P: RANKL and OPG regulation of bone remodeling in health and disease. Endocr Rev 2008;29:155192.

47 Rauch BH, Millette E, Kenagy RD, Daum G, Fischer JW, Clowes AW: Syndecan-4 is required for thrombin-induced migration and proliferation in human vascular smooth muscle cells. J Biol Chem 2005;280:1750717511. 